\title{
Humidity insensitive step-index polymer optical fibre Bragg grating sensors
}

Woyessa, Getinet; Fasano, Andrea; Stefani, Alessio ; Markos, Christos; Nielsen, Kristian; Rasmussen, Henrik K.; Bang, Ole

\section{Published in:}

Proceedings of SPIE

Link to article, DOI:

$10.1117 / 12.2194963$

Publication date:

2015

Document Version

Publisher's PDF, also known as Version of record

Link back to DTU Orbit

Citation (APA):

Woyessa, G., Fasano, A., Stefani, A., Markos, C., Nielsen, K., Rasmussen, H. K., \& Bang, O. (2015). Humidity insensitive step-index polymer optical fibre Bragg grating sensors. In Proceedings of SPIE (Vol. 9634). [96342L] SPIE - International Society for Optical Engineering. Proceedings of SPIE - The International Society for Optical Engineering https://doi.org/10.1117/12.2194963

\section{General rights}

Copyright and moral rights for the publications made accessible in the public portal are retained by the authors and/or other copyright owners and it is a condition of accessing publications that users recognise and abide by the legal requirements associated with these rights.

- Users may download and print one copy of any publication from the public portal for the purpose of private study or research.

- You may not further distribute the material or use it for any profit-making activity or commercial gain

- You may freely distribute the URL identifying the publication in the public portal 


\title{
Humidity insensitive step-index polymer optical fibre Bragg grating sensors
}

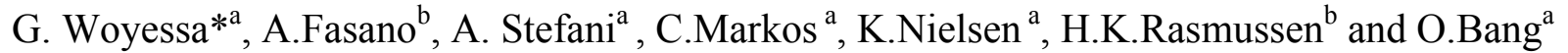 \\ ${ }^{a}$ Department of Photonics Engineering, Technical University of Denmark, Ørsteds Plads B343, 2800 \\ Kgs. Lyngby, Denmark; ${ }^{b}$ Department of Mechanical Engineering, Technical University of Denmark, \\ Nils Koppels Allé B404, 2800 Kgs. Lyngby, Denmark
}

\begin{abstract}
We have fabricated and characterised a humidity insensitive step index(SI) polymer optical fibre(POF) Bragg grating sensors. The fibre was made based on the injection molding technique, which is an efficient method for fast, flexible and cost effective preparation of the fibre preform. The fabricated SIPOF has a core made from TOPAS with a glass transition temperature of $134^{\circ} \mathrm{C}$ and a cladding from ZEONEX with a glass transition temperature of $138^{\circ} \mathrm{C}$. The main advantages of the proposed SIPOF are the low water absorption and good chemical resistance compared to the conventional poly-methyl-methacrylate (PMMA) based SIPOFs. The fibre has a minimum loss of $\sim 6 \mathrm{~dB} / \mathrm{m}$ at $770 \mathrm{~nm}$.
\end{abstract}

Keywords: Injection molding, Fibre fabrication, Polymer optical fibre, Fibre Bragg grating, Fibre optic sensor

\section{INTRODUCTION}

Interest in polymer optical fibre have increased considerably because of their very low processing temperature, high flexibility in bending, high fracture toughness, ease of handling, and non-brittle than that of glass fibre ${ }^{1,2}$. In addition, POFs are considered ideal candidates for biosensing applications due to their biocompatibility ${ }^{3,4}$. POFs have also high elastic strain limits and low Young's modulus, these properties giving them great potential for fibre Bragg grating based high strain and acceleration sensing applications ${ }^{5-9}$. The most common technique that have been used in the past to fabricate SIPOFs is by doping the core of a PMMA fibre with different active materials such as trans-4stilbenemethanol, Rhodamine B, benzil dimethyl ketal(BDK), etc. for FBG sensors or broad band amplification applications ${ }^{10-12}$. SIPOFs that are made of PMMA have low operating temperature and affinity for water, which make them sensitive to humidity ${ }^{13}$. Thus, the response of FBG sensors based on these fibres presents strong dependence both on temperature and humidity ${ }^{13-15}$. Here we demonstrate for the first time the fabrication of a humidity insensitive SIPOF made of TOPAS grade $5013 \mathrm{~S}-04$ with $\mathrm{Tg}=135^{\circ} \mathrm{C}$ as a core and ZEONEX $480 \mathrm{R}$ with $\mathrm{Tg}=138^{\circ} \mathrm{C}$ as a cladding. The polymers TOPAS and ZEONEX belongs to the class of cyclic olefin copolymers $(\mathrm{COCs})^{16}$ and cyclo-olefin polymer(COP $)^{17}$,respectively. These polymers are a class of optical thermoplastics that are chemically inert and have a very low moisture uptake ${ }^{16-17}$. Fiber Bragg grating has been successfully demonstrated in TOPAS fibre ${ }^{18 .}$ It has been also demonstrated that different TOPAS grades have high operation temperature ${ }^{19}$ and are humidity insensitive ${ }^{20}$, which make them a potential candidates for humidity insensitive FBG sensors.

\section{STEP INDEX PREFORM AND FIBRE FABRICATION}

The SIPOF was fabricated in-house at DTU Fotonik. First a SI preform was prepared by injection molding technique. Preparation of SI preform involved casting ZEONEX granulates into solid rod ${ }^{21}$. The particular grade that has been used was ZEONEX ${ }^{\circledR} 480 \mathrm{R}$ produced by ZEON CORPORATION, which has a glass transition temperature (Tg) of $138^{\circ} \mathrm{C}^{22}$. This polymer is suitable for engineering applications requiring mechanical stability at high temperature. After casting, the solid rod was machined to a uniform bulk preform of $60 \mathrm{~mm}$ diameter and $100 \mathrm{~mm}$ length. Then a single hole with a diameter of $4 \mathrm{~mm}$ is drilled at the center of the preform. The second phases of preparation of SI preform involved injecting TOPAS ${ }^{\circledR}$ 5013S-04 into a $4 \mathrm{~mm}$ hole of prepared ZEONEX preform. TOPAS ${ }^{\circledR}$ 5013S-04 granulates is obtained

24th International Conference on Optical Fibre Sensors, edited by Hypolito José Kalinowski, José Luís Fabris, Wojtek J. Bock, Proc. of SPIE Vol. 9634, 96342L · C 2015 SPIE CCC code: $0277-786 \mathrm{X} / 15 / \$ 18 \cdot$ doi: $10.1117 / 12.2194963$ 
from TOPAS Advanced Polymers, Inc, and it has a glass transition temperature (Tg) of $134{ }^{\circ} \mathrm{C}^{23}$. Engel ES $80 / 25 \mathrm{HL}-$ Victory injection molding machine has been used for injecting the TOPAS into the host ZEONEX. These two materials have been chosen for several reasons. As TOPAS is cyclic olefin copolymer (COC) and ZEONEX is cyclo-olefin polymer (COP) they have a very close chemical, mechanical and optical properties. In addition, the selected grades of these polymers have almost the same glass transition temperature and very close refractive index with TOPAS 5013S-04 refractive index higher than ZEONEX 480R. Different injection temperatures were preliminarily tested with the aim of optimizing the transparency of TOPAS. Interestingly, a decrease in the injection temperature seemed to lead to increasing its transparency while being injected. Nevertheless, it was not possible to lower temperature too much, since TOPAS would become too stiff to be processed. The optimal injection temperature was found to be around $200{ }^{\circ} \mathrm{C}$. TOPAS was then injection molded into the central hole of the ZEONEX solid rod at an injection pressure slightly lower than the machine limit, which is approximately 2000 bar. Then the SI preform was first drawn to $5 \mathrm{~mm}$ cane. Then after the $5 \mathrm{~mm}$ cane is sleeved and drawn to a fibre of a diameter $150 \mu \mathrm{m}$. The core diameter of the fibre is $15 \mu \mathrm{m}$. The end facet of the TOPAS-ZEONEX SIPOF is shown in Figure 1.

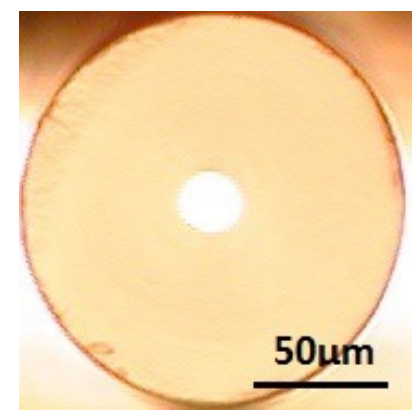

Figure 1. Microscope image of the step index TOPAS-ZEONEX polymer optical fibre

\section{FIBRE CHARACTERISATION AND FBG INSCRIPTION}

The transmission loss of the SIPOF was measured using the cut-back method. The light from Supercontinuum source (NKT Photonics A/S) was butt-coupled to SIPOF. The other end of the SIPOF coupled to standard single mode fibre, which is connected to Optical Spectrum Analyzer (OSA, Ando AQ6315A) to record the output transmission spectrum of the POF. The end face of the output SIPOF was cleaved with a custom-made cleaver at a temperature of $75^{\circ} \mathrm{C}$ which it has been shown to be optimum cleaving temperature for both the blade and the fiber ${ }^{24}$. The measured loss profile of the SI TOPAS-ZEONEX POF is shown in Figure 2. The minimum loss was measured to be $\sim 6 \mathrm{~dB} / \mathrm{m}$ at $780 \mathrm{~nm}$ and $10 \mathrm{~dB} / \mathrm{m}$ at $850 \mathrm{~nm}$.

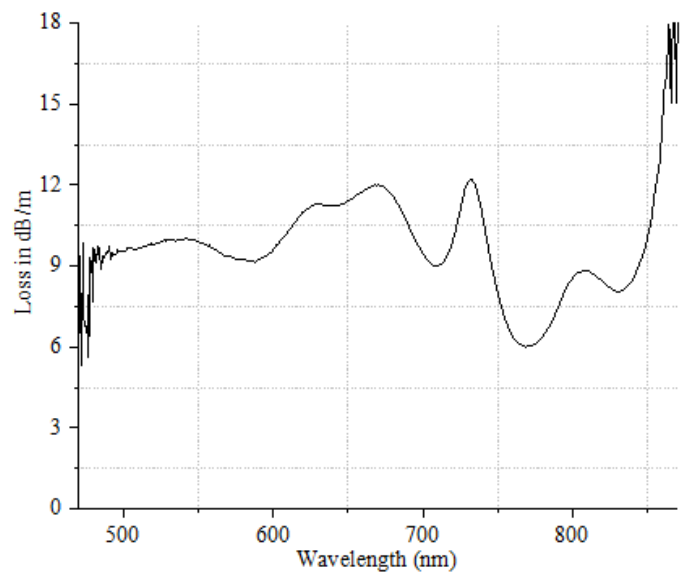

Figure 2. Measured transmission loss of step index TOPAS-ZEONEX polymer optical fibre 
Grating has also been inscribed in the fabricated SIPOF using phase mask technique. The technique we use for inscribing FBGs is the phase mask writing technique and it is the same configuration as it was used for fast FBG inscription in PMMA mPOF ${ }^{25}$. The phase mask used for inscribing grating in the SIPOF has $572.4 \mathrm{~nm}$ uniform period, and it is suitable for writing FBGs at $850 \mathrm{~nm}$ using a He-Cd $325 \mathrm{~nm}$ laser. Typical reflection spectrum of a $3 \mathrm{~mm}$ grating inscribed in the SIPOF is shown in Figure 3.

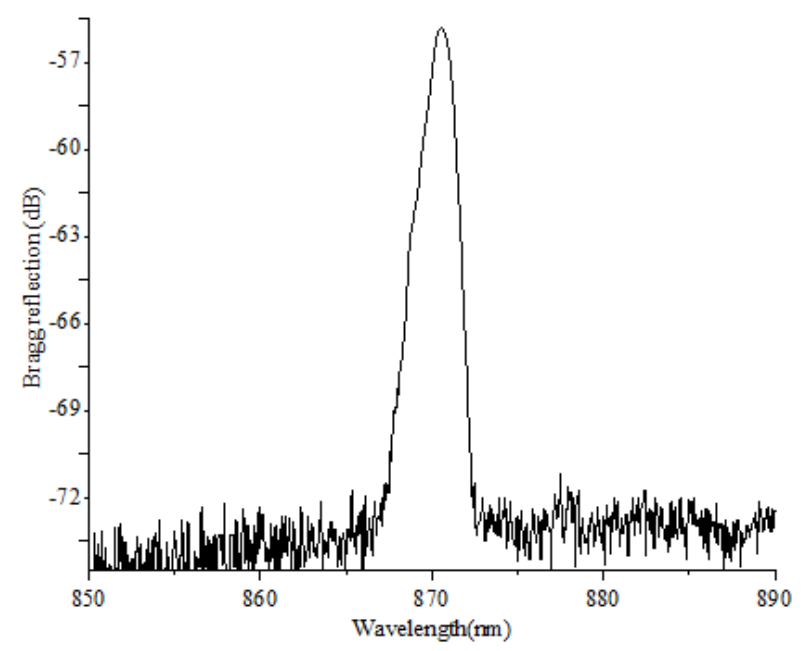

Figure 3. Reflection spectrum of the step index TOPAS ZEONEX polymer optical fibre

\section{CONCLUSION}

In this work, we have fabricated for the first time a humidity insensitive step index polymer optical fibre using injection molding technique. This technique provided a fast and flexible method of preparing step index preform. The fabricated step index polymer optical fibre has a core made from TOPAS 5013S-04 with a glass transition temperature of $134^{\circ} \mathrm{C}$ and a cladding from ZEONEX 480R with a glass transition temperature of $138^{\circ} \mathrm{C}$. The step index fibre has a minimum transmission loss of $6 \mathrm{~dB} / \mathrm{m}$ at $770 \mathrm{~nm}$ and $10 \mathrm{~dB} / \mathrm{m}$ at $850 \mathrm{~nm}$. The loss of the SIPOF can be further reduced by improving the fabrication technology and method. A fibre Bragg grating has also been inscribed in the step index TOPAZ ZEONEX polymer optical fibre. We believe that FBGs inscribed in this step index fibre are particularly suitable for sensing applications that require high operating temperature and very low moisture absorption polymer optical fibre Bragg grating.

\section{ACKNOWLEDGMENTS}

The research leading to these results has received funding from the People Programme (Marie Curie Actions) of the European Union's Seventh Framework Programme FP7/2007-2013/ under REA grant agreement n 608382.

\section{REFERENCES}

[1] Takezawa,Y., Tanno,S., Taketani,N., Ohara,S. and Asano,H., "Analysis of Thermal Degradation for Plastic Optical Fibres, " J. Appl. Poly. Sci.42(10), PP. 2811-2817(1991).

[2] Peters, K., "Polymer optical fibre sensors-a review, " In: Smart Mat. Struct., 20(1), 013002 (17 pp)2011.

[3] Emiliyanov, G., Høiby, P.E., Pedersen, L.H. and Bang, O. "Selective serial multi-antibody biosensing with TOPAS microstructured polymer optical fibres," Sensors 13 (3), 3242-3251 (2013).

[4] Markos,C., Yuan,W., Vlachos,K., Town,G.E. and Bang,O., "Label-free biosensing with high sensitivity in dual-core microstructured polymer optical fibres, " Opt. Express 19(8), 7790-7798 (2011). 
[5] Cusano,A., Cutolo,A. and Albert,J., [Fibre Bragg Grating Sensors: Recent Advancement, Industrial Applications and market Exploitation], Bentham Science Publishers, Chap. 15(2009).

[6] Xiong, Z., Peng, G. D., Wu, B., Chu, P. L., "Highly tunable Bragg gratings in single-mode polymer optical fibres," IEEE Photonics Technol. Lett. 11(3), 352-354 (1999).

[7] Dobb, H., Webb, D. J., Kalli, K., Argyros, A., Large, M. C., van Eijkelenborg, M. A., "Continuous wave ultraviolet light-induced fibre Bragg gratings in few- and single-mode microstructured polymer optical fibres," Opt. Lett. 30(24), 3296-3298 (2005)

[8] Stefani, A., Yuan, W., Markos, C., and Bang, O., "Narrow bandwidth 850-nm fiber Bragg gratings in fewmode polymer optical fibres, " IEEE Photonics Technol. Lett. 23(10), 660-662 (2011)

[9] Stefani, A., Andresen, S., Yuan, W., Herholdt-Rasmussen, N. and Bang, O., "High Sensitivity Polymer Optical Fibre-Bragg-Grating-Based Accelerometer," IEEE Photonics Technology Letters, 24(9), 763-765 (2012).

[10] Yu, J. M., Tao X. M. and Tam H. Y., "Trans-4-stilbenemethanol-doped photosensitive polymer fibres and gratings, " Opt. Lett., 29(2), 156-158 (2004).

[11]Liang, H.; Zheng, Z.; Li, Z.; Xu, j.; Chen, B.; Zhao, H.and Zhang, Q., "Fabrication and Amplification of Rhodamine B-Doped Step-Index Polymer Optical Fibres ," J. Appl. Polym. Sci., 93, 681-685(2004).

[12] Wang,T., Luo,Y., Peng,G.D. and Zhang,Q. "High-sensitivity stress sensor based on Bragg grating in BDKdoped photosensitive polymer optical fibre, " in Proc. 3rd Asia Pacific Opt. Sensors Conf., pp. 83510M-1$83510 \mathrm{M}-8(2012)$.

[13]Zhang, C., Zhang, W., Webb, D.J. and Peng, G.D., " Optical fibre temperature and humidity sensor, " Electronics Letters, 46, (9), pp. 643-. 644(2010).

[14] Webb,D.J., Kalli,K., Carroll,K., Zhang,C ., Komodromos,M., Argyros,A., Large,M., Emiliyanov,G., Bang,O.and Kjaer,E., "Recent developments of Bragg gratings in PMMA and TOPAS polymer optical fibres, "Advanced Sensor Systems and Applications III, Proc. of SPIE 6830, 683002 (2007).

[15] Webb,D.J., Kalli,K., Zhang,C., Komodromos,M., Argyros,A., Large,M., Emiliyanov,G., Bang,O. and Kjaer,E., "Temperature sensitivity of Bragg gratings in PMMA and TOPAS microstructured polymer optical fibres, " Photonic Crystal Fibres II, L9900 (2008).

[16] Khanarian,G., "Optical properties of cyclic olefin copolymers, " Opt. Eng. 40(6), 1024-1029 (2001).

[17] Anthony,J., Leonhardt,R., Argyros,A. and Large,M.C.J, " Characterization of a microstructured Zeonex terahertz fibre, " J. Opt. Soc. Am. B 28(5), 1013-1018 (2011).

[18] Johnson,I.P., Yuan,W., Stefani,A., Nielsen,K., Rasmussen,H.K., Khan,L., Webb,D.J., Kalli,K., and Bang,O., "Optical fibre Bragg grating recorded in TOPAS cyclic olefin copolymer, " Electron. Lett. 47(4), 271-272 (2011)

[19] C. Markos, A. Stefani, K. Nielsen, H. K. Rasmussen, W. Yuan, and O. Bang, "High-Tg TOPAS microstructured polymer optical fibre for fiber Bragg grating strain sensing at 110 degrees, " Opt. Express 21(4), 4758-4765 (2013).

[20] Yuan, W., Khan, L., Webb, D., Kalli, K., Rasmussen, H., Stefani, A. and Bang, O., "Humidity insensitive TOPAS polymer fibre Bragg grating sensor," Opt. Express 19, 19731-19739 (2011).

[21]Zhang,Y., Li,K., Wang,L., Ren,L., Zhao,W., Miao,R.., Large,M. and Van Eijkelenborg, MA. "Casting preforms for microstructured polymer optical fibre fabrication," Opt. Express, vol. 14, no. 12, pp. 5541$5547(2006)$.

[22] http://www.zeonex.com/

[23] http://www.topas.com/

[24] Stefani, A., Nielsen, K., Rasmussen, H.K. and Bang, O., "Cleaving of TOPAS and PMMA microstructured polymer optical fibres: Core-shift and statistical quality optimization," Opt. Communications, 285(7), 18251833 (2012).

[25] Bundalo,I.-L., Nielsen,K., Markos,C. and Bang,O., "Bragg grating writing in PMMA microstructured polymer optical fibres in less than 7 minutes, " Opt. Express 22(5), 5270-5276 (2014).

*gewoy@fotonik.dtu.dk; phone +454525 5735; 